\title{
Key Factors in Big Data Implementation for Smart City: A Systematic Literature Review
}

\author{
Yulida Safitri* \\ ${ }^{*}$ Pontianak City Government, Indonesia.
}

\section{INFORMASI ARTIKEL}

\section{Article history:}

Data submission : August 21, 2019

$1^{\text {st }}$ revision: October 13, 2020

Accepted: January 2021

Available online: May 31, 2021

Keywords: Smart City; Big Data; Big Data Implementation; Opportunities; Challenges; Key Factors for Implementation.

\begin{abstract}
Many governments implement smart city concept in their daily operation. As the concept continues to develop, smart cities all over the world are now starting to utilize big data. Learning from their private counterparts that already ahead in harnessing the potential benefits of big data implementation, smart cities begin the transformation of implementing big data. The purpose of this research paper is to: 1) Review the possible opportunities offered by big data implementation in smart city, 2) Review the challenges that smart city need to solve in utilizing big data, 3) Develop a framework that addresses the key factors in successful big data implementation in smart city. This research paper produces a framework that addresses several key factors that smart city government should consider ensuring success when implementing big data based on the proposed model indicators in private sectors. This framework consists of key factors of big data implementation for smart city which are top management support, organizational change, privacy and security, data availability and quality, cost, skillset and knowledge, big data policy, and technological infrastructure. It is important to have an understanding that these key factors correlate each other and are equally important.
\end{abstract}

2021 FIA UB. All rights reserved.

\section{Introduction}

The more advance use of Information and Communication Technology (ICT) that connects to the internet allows smart city to collect tremendous amount of data, known as big data. Big data is massive amount of data that vary in terms of $3 \mathrm{Vs}$; volume, velocity, and variety (Halaweh \& Massry, 2015). Private sectors are those that have already implemented big data in their operation. However, big data implementation in public sectors, especially in smart cities are rather new.

As a new phenomenon, the implementation of big data varies from one smart city to another in different countries. Many smart cities in the world have implemented big data in their operation by collecting data related to urban living and stakeholders then utilizing the data for useful contents. Cities like Seoul, San Fransisco, Rio de Jenairo, Santander in Spain, and Cosenza in Italy are among those which have benefited from big data (Lim, Kim, \& Maglio, 2018). It is without a doubt that big data brings many promising benefits that can enhance the performance of smart city. However, big data also comes with fundamental challenges in their implementation process in smart city. If organizations can solve these challenges properly, it means that the organizations successfully implement big data. Therefore, challenges may represent the success factors of big data implementation in organization.

Indonesia is among those countries that have just started transforming its cities to be smart cities. It has been two years since the government first initiated the 100 Smart-City Movement under Indonesia multiple-

\footnotetext{
* Corresponding author email: yulidasafitri@student.ub.ac.id
} 
ministry collaboration; Ministry of Communication and Informatics, Ministry of Home Affairs, National Development Planning Agency, Ministry of Administrative and Bureaucratic Reform, Ministry of Public Works and Public Housing, and Ministry of State Secretariat (Indonesia Ministry of Communication and Informatics, 2017). Therefore, smart cities in Indonesia should have worked with big data in day-to-day operation by now.

To respond the latest development on big data implementation in smart city, Indonesia accommodates big data by establishing open data portal (www.data.go.id) known as One Data Indonesia. This data portal operates under Indonesia President Regulation number 39 in the year 2019 as its legal framework. Based on the regulation, Indonesia one data portal acts as a medium where both government and public can access government data. Here Indonesia government, from the central to local governments, ministries and government institutions, acts as both data producer and user. Therefore, smart cities in Indonesia can now work not only with the data obtained by the cities themselves, but also with massive amount of data provided in the open data portal.

Despite the continuous growth of big data implementation in smart city, the understanding about the opportunities and challenges from big data remains limited. Several studies have investigated the implementation of big data based on the opportunities and challenges mainly in private sectors (Halaweh \& Massry, 2015; Gandomi \& Haider, 2014; LaValle, et al., 2011). Moreover, study about key factors that affect big data implementation in smart city is also limited. Therefore, I argue that there is a gap in literature when it comes to understanding key factors influencing big data implementation in smart city.

This research paper aims to answer the research question on what the key factors for successful big data implementation in smart city are. To answer the question, I will examine and analyze through Systematic Literature Review (STR) approach to investigate the following questions (1) What are the opportunities that smart city will gain after implementing big data? (2) What are the challenges that smart city need to overcome in implementing big data? A conceptual framework about key factors for successful big data implementation in smart city will be the result of this research paper. Thus, smart cities in Indonesia can use the framework to start big data implementation.

\section{Discussion}

\subsection{Smart city}

As the smart city concept continues to spread around the world, there is still no single way to define what smart city concept is. There are two major perspectives to perceive smart city: people's perspective and technological perspective (Al Nuaimi et al., 2015). Technological perspective has been used in the early development of smart city concept. In the early emergence of smart city in 2005, the concept refered to the implementation of complex information sytems in order to integrate the city infrastructure operation and services such as buildings, transportation, electricity, water, and public safety (Harrison \& Donnelly, 2010). Another explanation on smart city concept by IBM stated that smart city operates on the value of instrumentation of the system and digitization, interconnection, and intelligence (Dirks \& Keeling, 2009).

Technological perspective itself is not enough to cover all dimensions of smart city. Therefore, to understand the concept of smart city we should utilize people's perspective. The California Institute for Smart Communities and The Center of Governance at the University of Ottawa are among those who started to bring the importance of people and government in defining smart city (Albino, et al., 2015). The California Institute argued that communities could become smart as the city implement ICT in its design. Meanwhile, the Center of Governance University of Ottawa smart city should be approach using a strong government-oriented perspective. Thus, the concept of smart city intertwines both the utilization of technology and people (community and government) participation.

In 2019, Indonesia has already elected 100 cities across the country. These cities will implement smart city concept using the guidance in the 100-Smart City Movement Master Plan and get guidance from Indonesia Ministry of Communication and Informatics. The first phase of the selection was in 2017, whereas the Ministry selected 24 cities. In the following year, as for the second phase, 50 cities joined the list of Indonesia 100smart city Movement. In 2019, the list of 100-smart city is complete.

These cities have been actively involved in developing and implementing smart city concept in their regions (Mahesa, Yudoko, \& Anggoro, 2019). Local governments all over Indonesia develop their ICT to implement smart city concept. They develop applications that can be used to provide better public service, boost work efficiency and effectiveness, and provide public safety. Smart city utilizes technologies like social media, applications, sensor, and surveillance cameras to support their daily operation.

\subsection{Big data}

The implementation of ICT and Internet of Things (IoT) have allowed smart city to obtain tremendous amount of data. These data are huge in volume, complex in terms of both structured and unstructured, and they are 
difficult to manage and process using traditional database and software tools (Kumar \& Prakash, 2016).

There are many ways to define big data. One of them is, according to Doug Laney, big data sets are big in their $3 \mathrm{Vs}$; volume, velocity, and variety (Laney, 2001). This definition emphasizes more on the characteristic of the information involved within (De Mauro, Greco, \& Grimaldi, 2015). Volume refers to the size of the data, terabytes or petabytes of data. Velocity refers to whether the data being created real-time or near real-time. Variety refers to the diversity of the data, whether they are structured or unstructured (Kitchin, 2014).

\subsection{Big data in smart city}

\subsubsection{Big data opportunities in smart city}

Smart cities all over the world face the similar circumstances whereas they now must deal with big data. Several studies have acknowledged the fact that smart cities can gain several promising benefits from big data in certain fields like transportation, healthcare, education, and public safety (Kitchin, 2014; Al Nuaimi, Mohamed, \& Al-Jaroodi, 2015; Kumar \& Prakash, 2016; World Bank Group, 2017). Based on some literatures, there are four main opportunities that smart city can gain by implementing big data:

\subsubsection{Evidence-based policy making}

By implementing big data, smart city can improve its policy. It is because big data provides near real-time data and real-time data that can improve the accuracy of the policy (Kitchin, 2014; Giest, 2017; Idzalika, Pramestri, Amin, \& Riyadi, 2019). Big data offers the possibility to have predictive analysis (Hochtl, Parycek, \& Schollhammer, 2016). It means that smart city can combine all the insights gained from big data analysis to better plan the future policies. These insights were not possible to gained in past due to the limited ICT infrastructure that can support smart city in working with big data (Halaweh \& Massry, 2015).

Benefits of big data implementation are not only applicable in the planning phase of policy making but also in the implementation and evaluation (Hochtl, Parycek, \& Schollhammer, 2016). Smart city can now get a real-time response from society about newly implemented policy. Social media allow people within and outside the city juridiction to give feedback on the new policy. City government can know how well society accept or reject the policy. Through big data analytics, government can gain insights about the implementation fast and in details. As for the policy evaluation, smart city can conduct the evaluation in several periods of time instead of just happening at the end of the policy cylce (Hochtl, Parycek, \& Schollhammer, 2016).

\subsubsection{Better public service delivery}

The advancement of ICT in day-to-day smart city service can improve the citizens' quality of life through better and faster service (Al Nuaimi, Mohamed, \& AlJaroodi, 2015). The use of technologies such as surveillance cameras, censors, and social media platforms allow the city municipal to map the concerns that spread among the citizens, to get more information about current problems in society (Kitchin, 2014). The city government can have better understanding about the crucial issues in public services. Big data analytics provide detail analysis from the collected data then give the government insights that can be used to make decision. City government can now decide what actions do the city need to take on certain issue based on the latest even real-time data. The use of sensors and sensors networks allow smart city to collect information about weather, traffic, air quality, energy consumption, water consumption, and waste (Berntzen, Johannessen, \& Hogskolen, 2018).

Big data make public service evaluation easier for the smart city through complaint applications and or social media. City municipal can gain information on the exact location of the public service problem without having to conduct an old-fashion patrol. Data complaints allow the city to evaluate its service delivery for future improvement (Lim, Kim, \& Maglio, 2018).

\subsubsection{Better citizen engagement}

Before the development of ICT, the citizens were reluctant to participate and engage in the government operation due to the lack of trust. ICT allows the government to be more transparent in its operation; therefore, it improves people trust to the government. Multiple communication channels allow government to disseminate information about its work, policy, budgeting, and work performance to the public through open data portal (Fredriksson et al., 2017). This open data portal improves government transparency. Public can also monitor the government work and express their feedbacks, complaints, and appreciations through these communication channels such as social media and complaint application. This two-way communication provides the government with the opportunity to be more responsive to its public (World Bank Group, 2017).

\subsubsection{Easier city management}

The availability of real-time data mitigates some barriers in city daily operation. Big data makes it possible for the city to optimize work, automate work, measure employee performance, and conduct internal control and supervision (Maciejewski, 2017). For instance, the use of smart city budgeting application in Pontianak has made the mayor easier to monitor the city budget performance in each city organization in real-time. This 
can help the mayor in making decision and act accordingly. Another example is the surveillance cameras that installed in every office make it easier for the city to monitor its employees' work performance.

Sensors and surveillance cameras around the city assist the city to conduct its service more efficiently and more effectively. It is now possible for the city to generate data from the installed technologies to determine its operation (Lim, Kim, \& Maglio, 2018). Many countries around the world such as the US, Japan, South Korea, Singapore, and the UK, have tasted the fruitful outcomes from utilizing big data in their daily operation (Kim, Trimi, \& Chung, 2014).

\subsubsection{Big data challenges in smart city}

Big data comes with some challenges in the implementation. The city should understand and overcome these challenges to gain the big data potentials. There are many literatures addressing the challenges of big data implementation. There are some challenges that most literatures agree on, which are the data, technological infrastructure, and privacy and security (Al Nuaimi, Mohamed, \& Al-Jaroodi, 2015; Giest, 2017; Idzalika, Pramestri, Amin, \& Riyadi, 2019; Kumar \& Prakash, 2016; Hochtl, Parycek, \& Schollhammer, 2016; Lim, Kim, \& Maglio, 2018; Kitchin, 2014; Halaweh \& Massry, 2015; Maciejewski, 2017; Fredriksson et al., 2017; Chatfield, Reddick, \& Al-Zubaidi, 2015). However, there are other challenges that smart city will encounter in the implementation of big data, based on the revised conceptual framework for organizational capability challenges in transforming government through big data (Chatfield, Reddick, \& AlZubaidi, 2015).

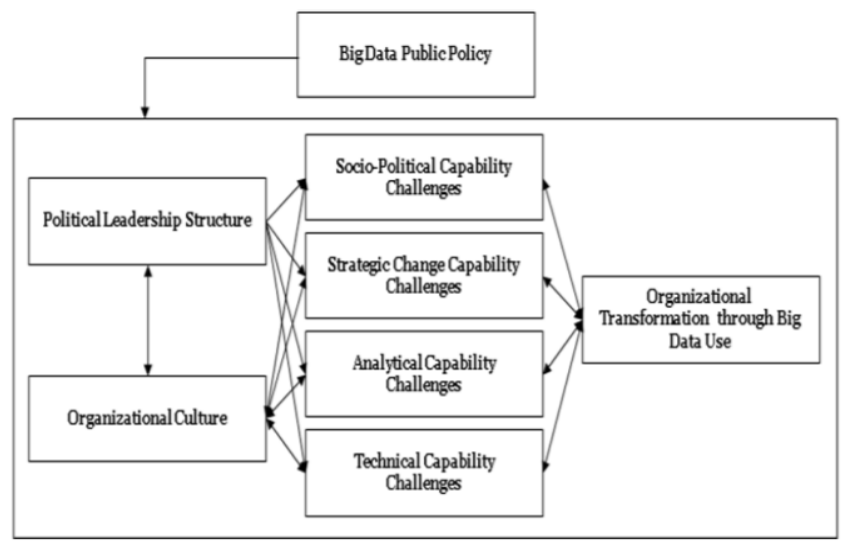

Figure 1. Revised conceptual framework for organizational capability challenges in transforming government through big data

\subsubsection{Socio-political capability challenges}

Socio-political capability challenges refer to issues related to privacy and security of the data. It is because data privacy and security relate closely to socio-political context, conceptual, legal, and technical significance (Chatfield, Reddick, \& Al-Zubaidi, 2015). Data privacy boundary is a big homework for the government to solve. To what extent government can access its citizens' data to enhance the public service is an important question that government need to address. Many citizens in smart city concern about their data privacy although they support the implementation of big data in the public service (Lim, Kim, \& Maglio, 2018).

As for the security issues, smart-city government must ensure the security of the data. Otherwise, the city can be very vulnerable of cyber-attacks (Kitchin, 2014). Big data sets contain much information on government and the people; therefore, smart city should provide high security policy to protect this valuable information (Al Nuaimi, Mohamed, \& Al-Jaroodi, 2015). Security issue is a challenge that smart city need to take seriously; otherwise, it can endanger their daily operation.

\subsubsection{Strategic change capability challenges}

Strategic changes talk mostly on the internal organization transformation (Chatfield, Reddick, \& AlZubaidi, 2015). By implementing big data, organization must go through dramatic change in its operation. For example, in decision-making, organization should transform from traditional decision making based on decision makers' experience and knowledge to data driven decision making (LaValle, et al., 2011). Many governments struggle with this challenge since the top management has been costumized in implementing old fashion decision-making for many years. Moreover, many top level administrator are also senior in terms of age therefore it may be rather difficult for them to change the way they work.

Chatfield et al (2015) address the data strategy, data governane, and data sharing in the strategic change capability challenge. Data strategic refers to the way organization utilize the data. The recent condition within public sectors is that civil servants and policy makers do not have a clear vision on how they can strategicly utilize big data in smart city operation (Giest, 2017). Data governance covers the issues related to data management. According to Chatfield et al (2015), government should provide a comprehensive data governance model that covers the issues of accuracy, privacy, data reuse, data preservation, and data development standard. On the matter of data sharing, it is rather a complicated issue since it is related to cooperation, colaboration, and communication between institution. Government data come from multiple sources. The challenge is on how the government can break the ego of each organization to share its data. Many government organizations are rather reluctant to share their data to other organizations (Maciejewski, 2017). Moreover, according to Idzalika, Pramestri, 
Amin, \& Riyadi (2019), private enterprises own most of big data sets, smart cities have to face this barrier if they want to use these data sets.

\subsubsection{Analytical capability challenges}

It refers to the human resources knowledge and skill, and the cost of big data implementation (Chatfield, Reddick, \& Al-Zubaidi, 2015). The barriers on knowledge and skill not only come from within the government employee but also from the society. Nowadays, most government employees are not equipped with the skill set and knowledge to work with big data since big data is a new phenomenon (Fredriksson et al., 2017). Therefore, smart city applications should meet the current condition of the city employees' technological expertise to be useful (Lim, Kim, \& Maglio, 2018).

In this literature review, we think that it is important to include society knowledge and skill in utilizing technology. Society acceptance on new applications will influence big data implementation in smart cities (Lim, Kim, \& Maglio, 2018). Whether or not the people willing to use the application is an issue that government need to address.

As for the cost, big data implementation requires big investment in both the technology and the human resources. In terms of technology, the smart city should be able to provide sufficient technological infrastructure, which is not come in low price (Chatfield, Reddick, \& Al-Zubaidi, 2015). Moreover, the cities also need to provide the human resources who can work with the big data. They either should hire more people with data analysis and operation skills or upgrade their employees' skills in working with data (Kumar \& Prakash, 2016). These require the city to put extra budget in human resources.

\subsubsection{Technological capability challenges}

Chatfield et al. (2015) categorized data quality, extraction, reliability, and scalability in the technological capability challenges. The quality of the data will influence the trustworthiness of the information used and shared by the smart city (Lim, Kim, \& Maglio, 2018).

Data extraction relates to the challenge of the organization in gaining knowledge from the data set (Chatfield et al., 2015). Data extraction concerns on data analysis algorithm and software in extracting valuable information and meaning from big data. Data scalability relates to how the organization can work with unstructured data (Chatfield et al., 2015).

\subsubsection{Big data policy}

Policy related to big data is still rather new. Therefore, many nations are still working on constructing the appropriate big data policy (Chatfield et al., 2015). The absence of big data policy can hinder the smart city government in its big data implementation. For instance, in the issue of data sharing, the absence of big data policy can hinder the data sharing within the government agencies, between central and local governments, and private public (Idzalika et al., 2019).

Big data policy is not only about data sharing but also about cooperation in data mining and analysis with private enterprise. Many governments such as Jakarta, Bandung, in Indonesia and Rio de Janeiro, Brazil cooperate with technological companies like IBM in big data implementation. Therefore, there is a possibility of technological dependency that may compromise government operation (Kitchin, 2014).

\subsubsection{Political leadership structure}

When we talk about big data in public sector, it is impossible to separate the process with the political leadership aspect. Smart city will likely to face more challenges in big data implementation if the political leaders do not show any commitment, have clear strategic vision in harnessing big data potentials and eagerness to innovation (Chatfield et al., 2015).

\subsubsection{Organizational culture}

According to Chatfield et al. (2015), organizational culture has more emphasize on the innovation culture within the organization. The innovation culture may apply in multiple aspects within the organization and in all level of hierarcy. The current condition within smart city governments is the lack of innovation which can hinder the big data implementation

\subsection{Key factors in big data implementation}

Literatures that address the key factors in big data implementation for smart city are limited. The available framework only covers the indicators of successful big data implementation in private sectors. Therefore, in this section we will provide a framework that represents key factors in big data implementation for smart city. We use proposed model of indicators by Halaweh and Massry (2015) which based the model development of big data implementation in private sectors.

In this research paper, to construct a proposed framework of key factors of big data implementation in smart city, we first analyze the challenges in the big data implementation in smart city. Those challenges represent the key success factors if tackled properly (Halaweh \& Massry, 2015). These key factors include:

\subsubsection{Top management support}

This factor represents whether the top management or the city leader has clear visions and objectives on big data implementation. In the context of Indonesia smart city, the city mayor, the provincial government, ministries, and the president should support the big data 
implementation. This support should be all the way from the top leader to the local government level, otherwise, the implementation of big data will likely fail.

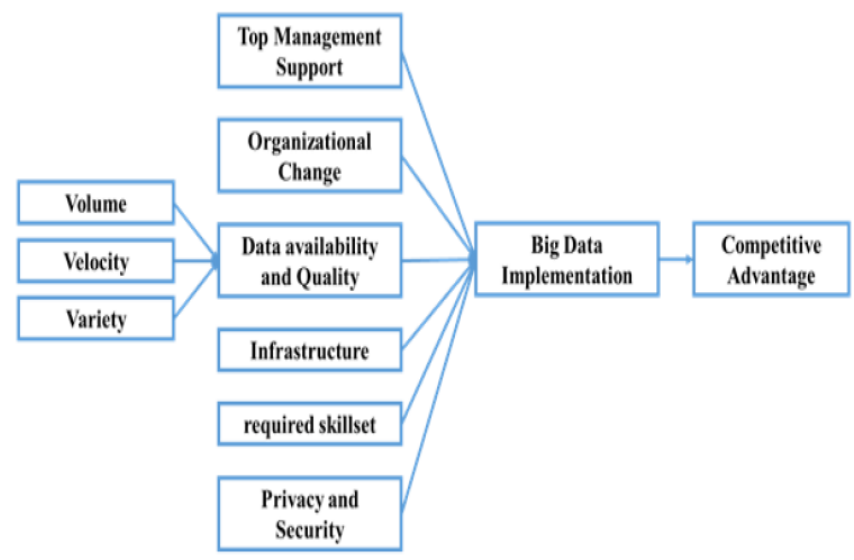

Figure 2: Proposed Model Indicators (Halaweh \& Massry, 2015)

\subsubsection{Organizational change}

This factor represents the willingness of the whole organization to transform under the big data implementation. When a smart city decides to implement big data in its daily operation, organizational change becomes inevitable. The city managements should plan the change ahead to ensure a smooth transformation. The organizational change can take place in the organization structure, individuals, and decision-making process.

\subsubsection{Data availability and quality}

This factor addresses the issue related to data. To implement big data successfully in its operation, smart city should ensure that it has enough data with proper quality. Moreover, the smart city should also ensure the validity and reliability of the data so that it can harness the potentials of big data.

\subsubsection{Technological infrastructure}

Technological infrastructure is crucial in determining the success of big data implementation. Some smart cities such as Bandung and Jakarta even cooperate with a leading technology company, IBM, to ensure the big data implementation. Technological infrastructure will determine whether the implementation can be success or fail.

\subsubsection{Cost}

The smart city works under a government budget. Therefore, many times the financial capability is among the key factors in big data implementation. The budget that government willing to allocate for big data implementation determine outcome.

\subsubsection{Skillset and knowledge}

This key factor represents the readiness of the smart city human resources in working with big data. The absence of sufficient data professionals will only bring the big data implementation to failure.

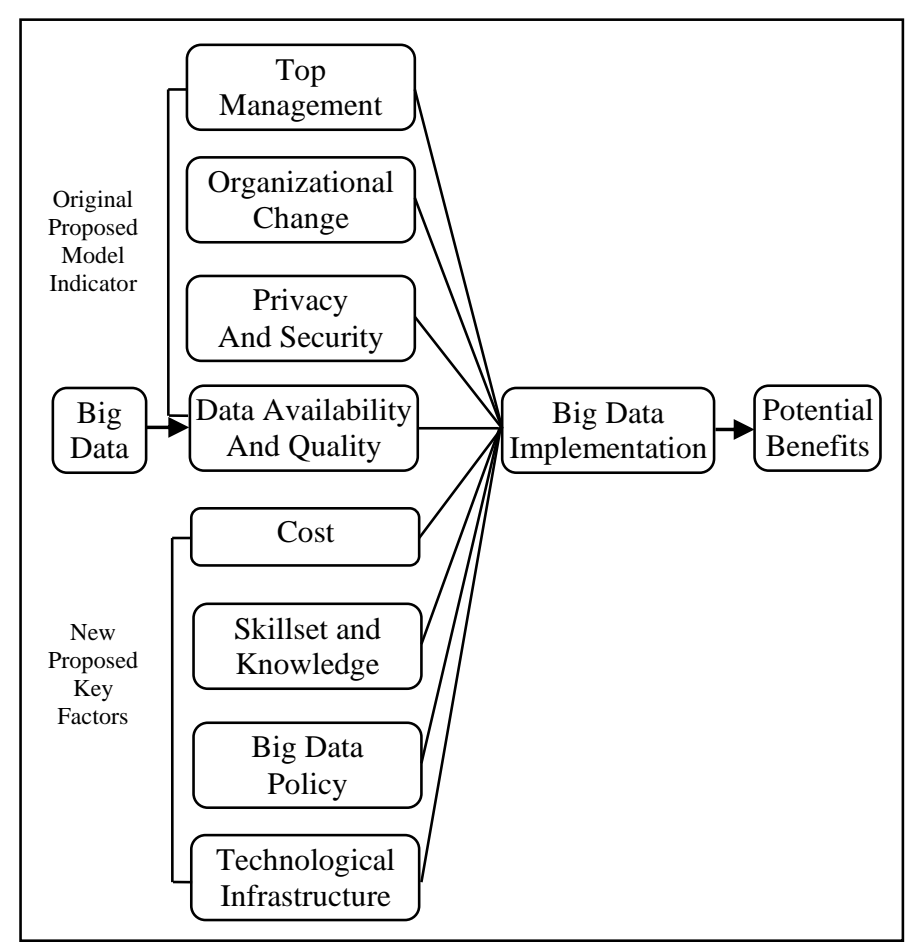

Figure 3: Proposed conceptual framework of key factors in big data implementation for smart city

\subsubsection{Big data policy}

The availability of policy and regulation related to big data implementation plays an equally important role in determining the success. It is because policy can provide the clear legal framework in data government-togovernment (G2G) data operation, government to corporate data operation, and government to public data operation. In addition, big data policy provides the smart city with clear standard on the data, code of conducts, and procedures in operating with big data.

\subsubsection{Privacy and security}

Smart city government should provide proper data security system that can prevent data leakage and hack in the future both from inside and outside of organization. As for the privacy issue, boundary about privacy violation should be available to prevent future allegation regarding privacy breach.

Based on the explanation above, we develop a proposed conceptual framework that represents the key factors in big data implementation for smart city in the figure below. All key factors are equally important and interconnected. Smart city should pay attention to all 
factors to ensure the successful big data implementation and harness the potential benefits.

\section{Conclusion}

Smart city cannot protect itself from big data. It is because smart city through its technology will collect massive amount of data. Therefore, it is important for the smart city to have a sufficient preparation in working with big data. However, the research related to this issue is rather limited. As an attempt to cover this gap, this research paper explored the opportunities that smart city can harness through big data implementation by providing key factors in successful big data implementation. However, understanding the opportunities themselves is not enough. This research paper explored on the potential challenges that smart city will face once it decides to implement big data. These challenges further represent the key factors of successful big data implementation once smart city can tackle them down. These key factors are equally important. Therefore, smart city should be able to address all the factors to ensure successful big data implementation.

Future research in this topic is highly recommended since there are still limited literatures covering the field of big data in smart city especially addressing the key factors for successful implementation. Future research may use quantitative research methods to test the framework and verify the validity of each key factor in several smart cities with different characteristics. We also encourage further research using qualitative method to further explore and develop the framework. Future researcher may interview city leaders, decision makers, and experts in big data implementation to gain more knowledge on the key factors in successful big data implementation.

\section{References}

Al Nuaimi, E., Mohamed, N., \& Al-Jaroodi, J. (2015). Applications of Big Data to Smart Cities. Journal of Internet Services and Applications, 1(1)5-12.

Albino, V., Dangelico, M., \& Berardi, U. (2015). Smart Cities: Definitions, Dimensions, Performance, and Initiatives. Journal of Urban Technology, 1(1) 3-6.

Chatfield, A., Reddick, G., \& Al-Zubaidi, H. (2015). Capability Challenges in Transforming Government Through Open and Big Data: Tales of Two Cities. Thirty Sixth International Conference on Information Systems.

De Mauro, A., Greco, M., \& Grimaldi, M. (2015). What is Big Data? A Consensual Definition and A Review of Key Research Topics. AIP Publishing.

Dirks, S., \& Keeling, M. (2009). A Vision of Smarter Cities: How Cities Can Lead the Way into a Prosperous and Sustainable Future. IBM Global Business Services.
Fredriksson, C., Mubarak, F., Touhimaa, M., \& Zhan, M. (2017). Big Data in The Public Sector: A Systematic Literature Review. Scandinavian Journal of Public Administration, 1(1)39-60.

Gandomi, A., \& Haider, M. (2014). Beyond The Hype: Big Data Concepts, Methods, and Analytics. Elsevier.

Giest, S. (2017). Big Data for Policy Making: Fad or Fasttrack? Springer, 1(3)367-382.

Halaweh, M., \& Massry, E. (2015). Conceptual Model for Successful Implementation of Big Data in Organizations. Journal of International Technology and Information Management, 1(3)21-34.

Harrison, C., \& Donnelly, A. (2010). A Theory of Smart Cities. 55th Annual Meeting of the International Society for the Systems Sciences.

Hochtl, J., Parycek, P., \& Schollhammer, R. (2016). Big Data in The Policy Cycle: Policy Decision Making in The Digital Era. Journal of Organizational Computing and Electronic Commerce, 9(1)147169.

Idzalika, R., Pramestri, Z., Amin, I., \& Riyadi, Y. (2019). Big Data for Population and Social Policies. Pulse Lab Jakarta.

Indonesia Ministry of Communication and Informatics. (2017). Buku Panduan Penyusunan Master Plan Smart City Gerakan Menuju 100 Smart City. Indonesian Ministry of Communication and Informatics.

Kim, H., Trimi, S., \& Chung, H. (2014). Big-Data Applications in The Government Sector: A Comparative Analysis among Leading Countries. ResearchGate, 78-85.

Kumar, S., \& Prakash, A. (2016). Role of Big Data and Analytics in Smart Cities. International Journal od Science and Research, 1(3)12-22.

Laney, D. (2001). 3D Data Management: Controlling Data Volume, Velocity, and Variety. Application Delivery Strategies by META Group Inc.

LaValle, S., Lesser, E., Shockley, R., Hopkins, S., \& Kruschwitz, N. (2011). Big Data, Analytics and The Path from Insights to Value. MIT Sloan Management Review, 1(3)22-23.

Lim, C., Kim, J., \& Maglio, P. (2018). Smart Cities with Big Data: Reference Models, Challenges, and Considerations. Elsevier.

Maciejewski, M. (2017). To Do More, Better, Faster, and More Cheaply: Using Big Data in Public Administration. Sage, 1(1)120-132.

Mahesa, R., Yudoko, G., \& Anggoro, Y. (2019). Dataset on the sustainable smart city. Elsevier.

World Bank. (2017). Big Data in Action for Government: Big Data Innovation in Public Services, Policy, and Engagement. World Government Summit. World Bank. 